\title{
Drug and therapeutics committees in Nigeria: evaluation of scope and functionality
}

Joseph O. Fadare ${ }^{\star 1}$, Olayinka Ogunleye ${ }^{2}$, Reginald Obiako ${ }^{3}$, Samuel Orubu ${ }^{4}$, Okezie Enwere ${ }^{5}$, Adetutu A. Ajemigbitse ${ }^{6}$, Johanna C. Meyer ${ }^{7}$, Ehijie Enato ${ }^{8}$, Amos Massele $^{9}$, Brian Godman ${ }^{10,11}$, Lars Gustafsson ${ }^{10}$

1Department of Pharmacology and Therapeutics, College of Medicine, Ekiti State University, AdoEkiti, Nigeria.

2Department of Pharmacology and Medicine, Lagos State University College of Medicine and the Teaching Hospital, Ikeja, Lagos.

${ }^{3}$ Department of Medicine, Clinical Pharmacology Unit, Ahmadu Bello University, Zaria, Nigeria.

${ }^{4}$ Faculty of Pharmacy, Niger Delta University, Bayelsa State, Nigeria.

${ }^{5}$ Department of Medicine, Imo State University, Orlu, Imo State, Nigeria.

${ }^{6}$ Department of Pharmacy, National Hospital Abuja, Abuja, Nigeria.

${ }^{7}$ School of Pharmacy, Sefako Makgatho Health Sciences University, South Africa.

${ }^{8}$ Department of Clinical Pharmacy and Pharmacy Practice, Faculty of Pharmacy, University of Benin, Benin City, Nigeria.

${ }^{9}$ Department of Clinical Pharmacology, School of Medicine, University of Botswana, Gaborone, Botswana.

${ }^{10}$ Division of Clinical Pharmacology, Department of Laboratory Medicine, Karolinska Institutet, Stockholm, Sweden.

${ }^{11}$ Strathclyde Institute of Pharmacy and Biomedical Sciences, University of Strathclyde, Glasgow, United Kingdom.

${ }^{*}$ Corresponding author: Joseph O. Fadare; Department of Pharmacology and Therapeutics; College of Medicine, Ekiti State University, Ado-Ekiti, Nigeria. Email: joseph.fadare@eksu.edu.ng; jofadare@gmail.com. Tel: +2348138048127

(Accepted for publication - Expert Review of Clinical Pharmacology)

\section{Abstract}

Introduction: Inappropriate use of medicines remains a problem, with consequences including increasing adverse drug reactions (ADRs) and prolonged hospitalizations. The Essential Medicines List and Drug and Therapeutics Committees (DTCs) are accepted initiatives to promote the rational use of medicines. However, little is known about DTC activities in Nigeria, the most populous African country. Areas covered: A cross-sectional questionnaire-based study was conducted among senior pharmacists, consultant physicians and clinical pharmacologists in 12 leading tertiary healthcare facilities across Nigeria. Expert commentary: Six $(50 \%, 6 / 12)$ healthcare facilities had existing DTCs with three (50\%) having a sub-committee on antimicrobials. $75 \%$ had infection control committees, with presence even in centres without DTCs. Chairpersons and secretaries of the DTCs were predominantly physicians $(83.3 \%)$ and pharmacists $(100 \%)$ respectively. Hospital formularies were available in five facilities with DTCs, while one facility without a DTC had an Essential Medicines Committee responsible for developing and updating the hospital formulary. The evaluation of ADRs was undertaken by pharmacovigilance units in nine facilities. Overall, DTCs were present in only half of the surveyed facilities and most were performing their statutory functions sub-optimally. The functioning of DTCs can be improved through government directives and mechanisms for continuous evaluation of activities.

Keywords: Rational use of medicines; Drug and therapeutic committees; Drug formulary; adverse drug reactions, Nigeria

\section{Introduction}

Inappropriate use of medicines is a global problem with wide consequences including adverse drug reactions (ADRs), therapeutic failure, prolonged hospitalization, development of drug resistance, inefficiencies in the procurement of medicines and increased healthcare costs $(1,2)$. Development of drug resistance, especially antimicrobial resistance (AMR), is a growing public health problem worldwide (3-6). 
The World Health Organization (WHO), with the Essential Medicines List (EML) and Drug and Therapeutics Committees (DTCs) concepts, initiated efforts to address the irrational use of medicines in the 1970s (7-10). A DTC is defined as a professional body that evaluates the clinical use of medicines, manages and supports evidence-based use of medicines through a formulary system and deals with policy issues of medicine use. The principal functions of DTCs include the evaluation and selection of drugs for the formulary, supporting the Rational Use of Medicines (RUM) in the hospital, as well as continuous medical education initiatives to improve the use and dispensing of medicines (11).

Studies in high income countries have highlighted the importance of DTCs in the promotion of RUM, and the cost-effective use of medicines, through learning with adherence to recommendations regarding prescribing enhanced through trust in those compiling the formulary (12-15). A few studies have described DTCs among lower and middle income countries (LMICs), but their functionality and mode of operation are poorly reported (16-18).

In Nigeria, there is considerable evidence regarding the inappropriate use of medicines. This is a concern since out of pocket payments (OOP) currently constitutes the major component of healthcare expenditure, negatively impacting on available choices of medicines to effectively treat both infectious and non-communicable diseases $(19,20)$. Consequently, any initiative that would positively impact on RUM in Nigeria should be a priority for the country. In this regard, the role of functional DTCs cannot be overemphasized. The National Drug Policy of Nigeria recognizes DTCs as a vital component with initial targets of institutionalizing the committees in secondary and tertiary healthcare facilities (21). However, presently there is little information regarding the presence and functionality of DTCs in hospitals or other health care facilities in Nigeria. This lack of information was the basis for this study.

The main objective of this study was to determine the availability and functionality of DTCs among tertiary healthcare facilities across Nigeria. The findings can be used to guide future activities in Nigeria to enhance the appropriate use of medicines as well as other African countries in similar circumstances.

\section{Methods}

\subsection{Study setting}

This study was undertaken among public sector tertiary healthcare facilities located across Nigeria, a country with an estimated population of over 187 million (22). Nigeria is divided into six geo-political zones and has 36 federal States and one Federal Capital Territory. Healthcare services are provided by both private and public healthcare facilities. The public healthcare system is stratified into three levels: primary, secondary and tertiary care. The primary level comprises health centres, while the secondary level comprises general hospitals. The tertiary healthcare level comprises Federal Medical Centres, University Teaching Hospitals, as well as specialized hospitals including orthopaedic and neuro-psychiatric hospitals. Presently, there are 50 university teaching hospitals owned by the federal or state governments (23). The tertiary level hospitals are the best-equipped facilities in terms of personnel and many have postgraduate training programmes for medical doctors, pharmacists, nurses and other healthcare staff. Consequently, if there are problems with fully functioning DTCs in tertiary hospitals, these are likely to be exacerbated in secondary care hospitals with less qualified personnel including typically a lack of clinical pharmacologists, pharmacists, and others well versed specialists in RUM.

\subsection{Study design}

A descriptive cross-sectional survey conducted between 1st and 30th April, 2016, using a selfadministered questionnaire was undertaken.

\subsection{Sample}

Purposive convenience sampling was undertaken, using hospitals with reliable personal contacts. Three tertiary healthcare facilities in each of the five geo-political regions (24) (Figures 1) of the country were selected for the study though questionnaires were sent to four in each zone to cater for non-responders. Tertiary healthcare facilities were selected as they have the most qualified cadre of personnel. The North-eastern zone of the country was excluded because of ongoing militant insurgency during the study period. 


\subsection{Data collection instrument}

A DTC Questionnaire (Annex 1), which is a standard instrument developed by the World Health Organization (WHO) and Management Sciences for Health (MSH), was used for this study $(25,26)$.

\subsection{Data collection process}

The questionnaires were sent by email to the focal persons of the selected institutions after initial contact by telephone. The focal person for each selected tertiary hospital was a senior pharmacist, a clinical pharmacologist or a consultant physician. A time frame of one month was allowed for the return of the completed questionnaires.

\subsection{Data analysis}

Data from the questionnaires were coded and entered into an MS Excel spreadsheet, cleaned, and imported into SPSS version 19 (IBM Corporation, Armonk, NY, USA) for analysis. Results were expressed as means, frequencies and percentages. For the non-quantitative data, content analysis using themes was used.

\subsection{Ethical considerations}

The study was exempted from ethical approval according to the National Code of Health Research Ethics of Nigeria because it dealt with information of existing programme or services with the primary aim of improvement in the outcomes (27).

\section{Results}

Responses were received from $12(60 \%)$ out of 20 tertiary healthcare facilities approached. These covered all the geopolitical zones apart from the North-eastern region (Figure 1). Six (50\%) of the 12 tertiary healthcare facilities had existing DTCs with various durations of operation (Range: 1-16 years). Four (66.7\%) of the DTCs in the six facilities with DTCs held meetings at variable intervals (monthly to 6-monthly), with minutes of the meetings being kept by all DTCs .

\section{Figure 1 - Geopolitical Zones of Nigeria and Hospitals Taking Part (adapted from (24))}

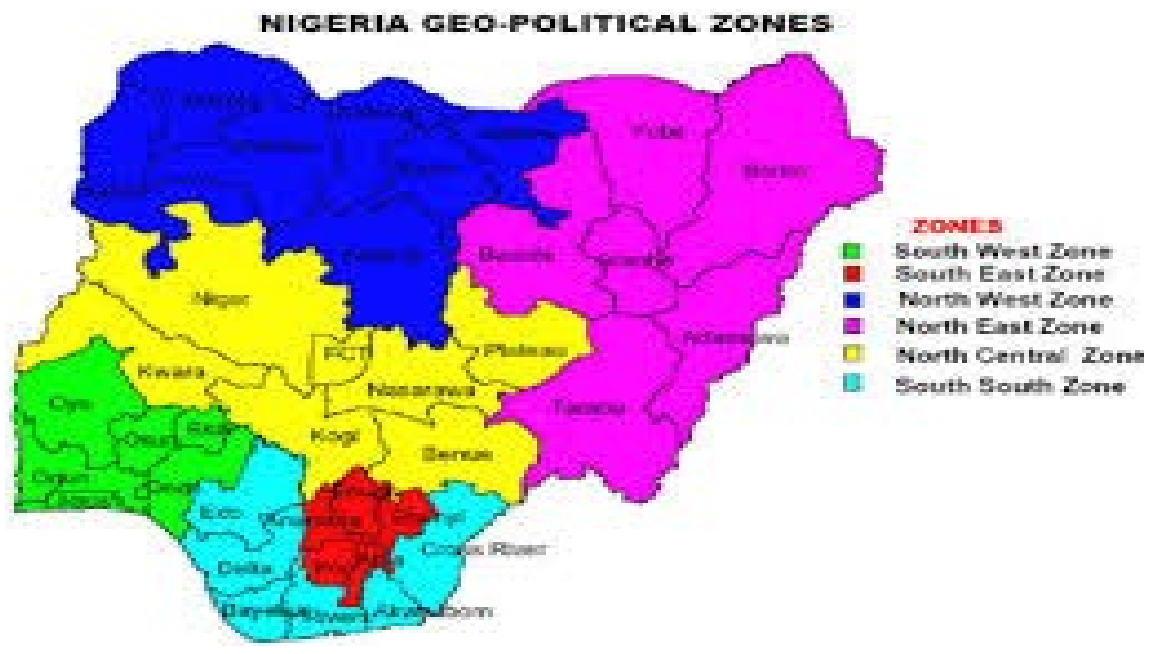

Hospitals taking part: South-West -4; South-East- 1; South-South- 1; North-Central- 4; North-West- 2

The chair and secretary of the DTCs were predominantly physicians $(83.3 \%)$ and pharmacists $(100 \%)$ respectively. Membership of the operational DTCs included physicians, pharmacists, nurses, laboratory technologists and administrative staff. Table 1 gives information about availability of DTCs and its' core functions in the surveyed healthcare facilities. Information about existence or otherwise of the core components of DTCs within each of the 12 participating hospitals including antimicrobial sub-committees, infection control sub-committees, operational guidelines and quality assurance of medicines are shown in Figure 2. 
Table 1: Information about availability of core components and functions of DTCs in Nigeria

\section{Questions/Statements}

Does your hospital have a DTC

Does your DTC have a Sub-committee on Antimicrobials?

Does your hospital have an Infection Control Committee?

Does your DTC have guidelines and procedures that regulate the functions of DTC

Does your hospital have a medicine formulary?

Is there a medicine information centre in your hospital?

Does your DTC have a policy for evaluating adverse drug reactions?

Does your DTC have established policies to assure product quality

Does your DTC participate in preparing technical specifications for procurement of Medicines?

Does your DTC participate in evaluating pharmaceutical costs and providing information back to the physician Does your DTC have established methods for periodically evaluating the use of medicines in the hospital and providing feedback to the physicians?

\section{Response (Yes)}

6

3

9

5

6

9

9

5

3

3

2

Response(No)

\author{
6
}

9

3

7

6

3

3

7

9

9

10

\title{
Figure 2 - DTC activities within each of the 12 participating Tertiary Hospitals
}

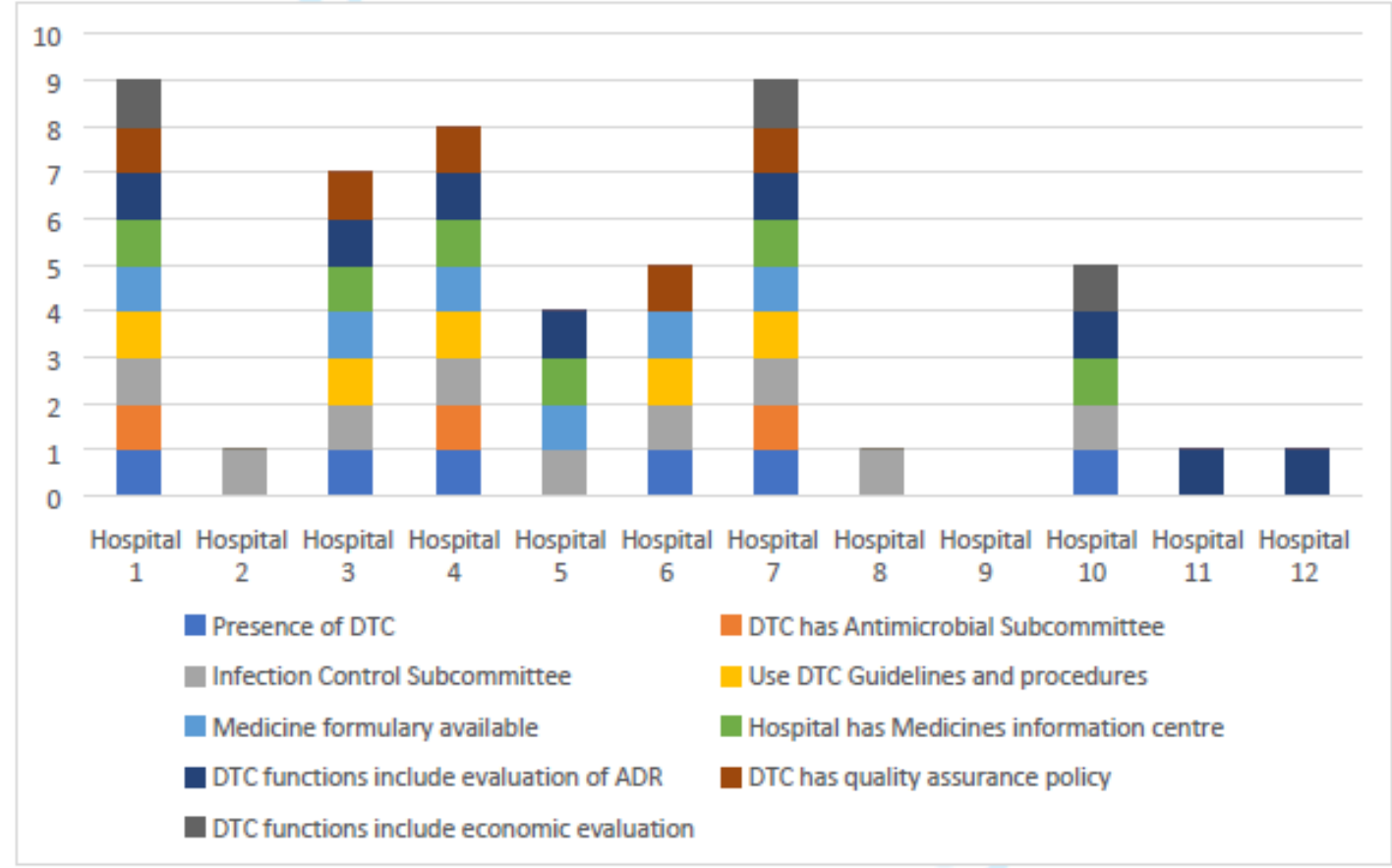

The reported functions of these DTCs included development and periodic review of hospital drug formularies, surveillance of antimicrobial use, pharmacovigilance activities and monitoring the use of narcotics . Other identified functions included the development of standard treatment guidelines (STGs) and infection control guidelines. Hospital formularies were available in five (83.3\%) healthcare 
facilities with DTCs, while one facility without a DTC had an Essential Medicines Committee, which was responsible for developing and updating the hospital formulary.

Medicines were listed in hospital formularies by generic name or International Non-proprietary Name (INN) in five (83.3\%) healthcare facilities, while brand (originator) names were included in one $(16.7 \%)$ facility. The hospital formularies, where they did exist, were modelled on the WHO Essential Medicines List (EML) concept. The number of chemical entities included in the hospital formularies, as specified by their INN, varied between 210 and 720 . The hospital formularies were usually available in hard copy and distributed to the hospital's clinics, wards and pharmacies. An electronic version of the formulary was not available in any of the healthcare facilities.

The time frame of updating the formulary varied from twice yearly to once every three years. Only two centres with DTCs had a revision every two years or less. The procedures for updating the formulary varied between the centres and included submission of requests by clinicians to the DTC. Pharmaceutical sales representatives also appeared to play a significant role in the process of updating the formulary through making presentations at various clinical departments and providing product information for evaluation by the DTC.

\section{Discussion}

The results from this survey showed that DTCs had not been instigated in half of the surveyed tertiary healthcare facilities, and were functioning sub-optimally where present. These findings are similar to results from a Brazilian study where only 29 out of 250 hospitals had DTCs (28). This is in contrast though to findings from studies carried out in Europe and Australia where DTCs were present in more than $90 \%$ of hospitals surveyed in both continents $(29,30)$, have to be present by law in Sweden (31), and are now required in all public sector hospitals in South Africa (18).

DTCs, especially its sub-committee on antimicrobials, are one of the main strategies for improving antimicrobial use and combating AMR in hospitals especially in low and middle income countries $(18,32)$. A major concern in Nigeria is that among tertiary facilities, only three hospitals had such a committee. However, we cannot say this with certainty until we evaluate the situation in these hospitals. This finding may though be due to possible overlap of the functions of the sub-committees and one dealing specifically with infection control, which was available in $75 \%$ of the surveyed healthcare facilities. These findings are similar to a Canadian study as well as a South African study, which revealed just about one third of DTCs have a sub-committee on antimicrobials $(18,33)$.

Members of DTCs in this study included physicians, pharmacists, nurses and laboratory scientists, which is similar to other countries $(33,34)$. While membership from all areas of medicine is important, trust and a transparent means of deliberation and decision making have been found to be core ingredients of successful DTC operations $(12,14)$. Most of the functions of DTCs reported in this study centered on drug formulary development and review, monitoring of ADRs and antimicrobial use, similar to studies conducted in Australia and Canada $(30,33)$. However, this is different from South Africa where the majority of activities centered on formulation and policies surrounding medicine use, development of formularies and monitoring medicines' expenditure (18).

One of the major functions of the DTCs is to assist with selecting cost-effective medicines, especially with the rising costs of new medicines, including those for cancer and orphan diseases $(13,28,31$, 35-37). However, this was not the case in our study, with only three out of 12 healthcare facilities currently performing any form of economic evaluation of proposed medicines, and this activity was not listed among the main functions of the DTCs. Similarly, a lack of expertise in pharmacoeconomics and evidence-based decision-making was identified as a challenge amongst hospital DTCs in a South African province (18). This omission is a potential concern in Nigeria as cost savings should be the priority of many developing countries where health insurance is not universal and a large percentage of healthcare spending is usually "out of pocket". This will be followed up in future research.

The overall lack of hospital formularies in many of the surveyed tertiary healthcare facilities is also a major concern. The lack of formularies suggests that there is no control in the number and scope of medicines that may be prescribed by physicians even in these tertiary healthcare facilities. In this situation, it becomes extremely challenging to monitor medicine prescribing in practice leading to potentially a lack of adherence to agreed treatment guidelines. The non-availability of electronic 
versions of hospital formularies is also an issue that needs urgent attention. With broadened access to the internet and smartphones in many LMICs, electronic version of formularies would likely increase access to them as well as promote their use among healthcare professionals. The positive aspect of using electronic versions of guidelines has been demonstrated in the Netherlands with their national antibiotic policy (38). There is also good adherence to prescribing guidelines in Sweden with suggested medicines listed in electronic formularies and monitored $(12,13)$. Amongst LMICs, clinical guidelines have been available in electronic format as a mobile application in South Africa since the end of 2015. These are now being updated continuously as changes are made to the EMLs and STGs (39) to help enhance appropriate medicine use. This is a consideration for all hospitals in Nigeria in the future with the extensive availability of mobile technology.

The number of medicines listed in hospital formularies in our study ranged from 210 to 720 . However, formularies at the higher end of the range may be counter-productive as the major objective of an EML or hospital formulary is to limit the number of medicines to the barest manageable minimum. This is exemplified by the latest versions of the Stockholm "Wise List" (excluding medicines for specialist conditions) and the Nigerian EML which contain 212 and 350 entities, respectively $(13,14$, 40). Observations of 13 DTC meetings in a South African province also revealed that all DTCs had an active formulary committee, working towards alignment with the national EML (18). This serves as an exemplar to Nigeria.

Encouragingly, almost all healthcare facilities with DTCs had medicines listed in the hospital formulary by generic name. Studies have shown that prescribing by generic name (INN) reduces healthcare costs significantly $(41,42)$, which is beneficial in LMICs where universal health care is very variable. However, the quality of generics has to be assured, similar to regulations in Europe and the US, for physicians to be comfortable to prescribe using the INN, as seen for instance in the UK with very high voluntary INN prescribing apart from a limited number of medicines (43). There have been concerns with the quality of generics in some LMICs, including Nigeria, impacting on their prescribing $(20,44)$. This needs to be urgently addressed in Nigeria for all key stakeholder groups to benefit from the increasing availability of standard medicines as low-cost generics.

The hospital formulary was updated infrequently as only two DTCs had revisions every two years or less. This is not surprising as the update of the fourth to fifth edition of the Nigerian National Essential Medicines List took over 7 years to complete (40). In addition, there seems to be no form of regulatory oversight regarding adherence to the National Essential Medicines List by healthcare facilities, with adherence to nationally agreed guidelines seen as an important marker of the quality of prescribing $(12-14,45,46)$. Pharmaceutical companies also play a significant role in the introduction of new medicines through presentations to clinical departments. The interactions between pharmaceutical sales representatives and physicians, and its implications regarding prescribing practices of physicians, have been widely reported in studies from developed countries and LMICs $(47,48)$. The quality of information provided by pharmaceutical sales representatives and their activities though remains a core issue alongside their influence $(49,50)$. This is also seen in Nigeria causing concern (51). These concerns have resulted in some hospitals banning promotional activities to improve future care (52). If this is not possible, the development and enforcement of guidelines for pharmaceutical sales representatives is an important DTC activity. However, this is not optimal across countries including South Africa, where only 11 of 19 hospital DTCs in one Province indicated this as a DTC activity (18). Having said this at national level in South Africa, dossiers from pharmaceutical companies are not considered in the selection of medicines and are regarded as having bias (53).

Overall, the safety profile, cost-effectiveness and efficacy of medicines are seen as very important considerations when introducing new medicines into the hospital formulary $(12,54-57)$. To do this effectively, members of DTCs must have access to, and be able to interpret clinical trials data, while some understanding of pharmacoeconomic analyses is also increasingly essential $(18,58)$. This again was not the case among most of the surveyed tertiary healthcare facilities in Nigeria. The periodic assessment of adherence to hospital drug formularies, using physicians' prescriptions, is also essential to promote RUM; however, only two healthcare facilities surveyed currently perform some form of periodic assessment. The usefulness of this approach is shown in Sweden with reports of high adherence levels (over 90\%) by physicians to the "Wise List" of medicines over a 15 -year period (14).

Encouragingly, most of the surveyed healthcare facilities had pharmacovigilance units that were functional. This is different to the situation that exists in a number of LMICs including public hospitals 
in South Africa (59). This is likely due to earlier concerted efforts by the Nigerian government, further corroborated by research findings on the information submitted to the National Pharmacovigilance Centre of Nigeria from many tertiary healthcare facilities $(60,61)$. Overall, periodic evaluation of medicine utilization including ADRs, with feedback to physicians, is useful for identifying medicine use patterns and associated problems such as the irrational use of medicines especially antimicrobials, potential drug-drug interactions and ADRs. This type of periodic evaluation was rarely performed in the surveyed tertiary hospitals which is a concern. Among DTCs in South Africa, both medicine utilization reviews $(58 \%)$ and monitoring of ADRs (35\%) are performed; however, again both are currently seen as sub-optimal (18). This urgently needs to be addressed in the future among Nigerian hospitals to improve future medicine use and patient safety.

It is evident from this study that the suboptimal availability and functionality of DTCs within Nigerian healthcare institutions needs attention. A national policy for the establishment and functioning of DTCs with clear directives, and enforced as a regulatory or managerial intervention, would pave the way for the rational use of medicines and preserve scare resources. South Africa is an example of a LMIC where a functional DTC is now a regulatory requirement in terms of quality standards for all health establishments, in addition to a national policy for DTCs $(59,62-64)$. These are considerations for the future in Nigeria, and we believe this study highlights such a need.

We are aware that this study has a number of limitations. This includes the fact that the number of tertiary healthcare facilities involved in this study is small and are all government owned. However, we believe the national spread of participating healthcare institutions is one of the strengths of this study as well as the initial selection of tertiary hospitals. The convenience sampling method is also a concern as it may not be statistically representative. However, the structure of tertiary healthcare facilities is similar throughout Nigeria and location so this is unlikely to affect the study outcome. However, future studies will address this issue. The issue of conflict of interest among members of DTCs and how they are handled was also not included in the questionnaire. This omission may affect to a certain extent the total picture of activities of DTCs emanating from this study. Future research on the activities of DTCs, especially of the qualitative type, is urgently needed to further investigate the understanding of stakeholders and dynamics of DTCs across both secondary and tertiary hospitals in Nigeria. This is also being planned for future projects alongside looking specifically at the influence of DTCs on improving the prescribing of specific medicine types such as antimicrobials. Never-the-less, we believe our findings are robust providing direction for the future not only in Nigeria but also wider.

\section{Conclusion}

DTC activities are currently limited in a substantial number of Nigerian tertiary healthcare facilities. In facilities with DTCs, many of the statutory functions and activities are currently not being carried out. This will continue to have a significant implication on the rational use of medicines in Nigeria, especially if these limited activities are seen, or worse, among secondary hospitals in Nigeria.

Consequently, there is an urgent need for all key stakeholders in the healthcare sector to work towards the resuscitation and proper functioning of DTCs in healthcare facilities across the country. The supervising Ministry can initiate this process by mandating DTC activities in the first instance among government-owned tertiary level hospitals. They should be encouraged to instigate functioning DTCs within a specific time frame, especially among hospitals where such committees are currently non-existent or very limited. This builds on examples in other countries. There should also be measurable outcomes, including agreed treatment adherence rates to national guidelines in priority disease areas, robust systems in place for placing new medicines onto formularies, monitoring medicine utilization against agreed standards of care and feeding the findings back to physicians. In addition, generally educating physicians on the rational use of medicines. We will be using the findings from these studies to explore this with relevant Ministry of Health personnel, building in proactive examples from other African countries.

\section{Expert Commentary}

The irrational use of medicines increases healthcare costs and may negatively impact on patient outcomes. DTCs play an essential role in promoting rational and cost-effective use of medicines worldwide. This is very important in LMICs such as Nigeria where universal health care is lacking. The results of this study show the absence of DTCs in half of the surveyed tertiary facilities with poor 
functionality in centres where available. There were also major issues with antimicrobial subcommittees, the ability to undertake pharmacoeconomic evaluations, and the availability of hospital formularies. In addition, the standard operating procedures were not well established in centres in tertiary hospitals with DTCs. These issues are a concern since if sub-optimal practices happen in tertiary facilities, the situation in secondary hospitals is likely to be worse. On the positive side, most centres had functioning drug information centres and pharmacovigilance units operating as separate entities. Overall findings of this study show that a lot more needs to be undertaken in the area of policy implementation and monitoring regarding DTCs in Nigeria to improve future care. Getting DTCs started and operational in healthcare facilities in the country will promote more cost-effective and rational use of medicines, logical uptake of new medicines and overall improve the quality of care and outcomes of patients. Future directions for research include assessing the knowledge and perspectives of healthcare workers on DTCs, as well as qualitative studies among DTC members to assess the processes of decision making and the level of implementation of their decisions. Introduction of new and expensive medications is a major function of the DTC; research into the patterns or procedures for introducing new medicines into healthcare facilities is something to be looked into in the near future in Nigeria building on activities among European countries.

\section{Five-year View}

We see DTCs evolving over the next five years in Nigeria with strides to improving access to medicines. However, the extent of such activities will depend on the influence and activities within the Nigerian Ministry of Health and translated down via directives and initiatives. The extent of DTC activities across all hospital sectors will also depend on the education of physicians and pharmacists whilst at Medical School or University. We do see greater physician education around the rational use of medicines to enhance the functioning of DTCs in Nigeria in the future. We have seen developments in the area of pharmacovigilance, and expect such developments with DTCs to assist with DTC activities in Nigeria in the future especially with concerns with current antimicrobial use in Nigeria and the subsequent impact on resistance rates and associated morbidity, mortality and costs in hospitals. The rates of non-communicable diseases are also a growing concern in LMICs including Nigeria impacting on morbidity and mortality, and again it is likely that DTC activities will involve to enhance the management of such patients in the future.

We will continue to monitor the progress being made with DTC activities over the coming years through undertaking a number of planned studies on several critical aspects of DTCs. The results of these studies, when presented to stakeholders in the healthcare sector in Nigeria, will likely lead to expect greater involvement of the government especially in the area of making and enforcement of legislation in this regard.

\section{Key issues}

- This study shows the absence of DTCs in half of the surveyed healthcare facilities and poor functioning where present

- Only $3(50 \%)$ healthcare facilities had a sub-committee on antimicrobials while there was an overall lack of hospital formularies

- Economic evaluation of medicines was only currently been undertaken in $3(25 \%)$ of the surveyed healthcare facilities

- Pharmacovigilance and Drug Information units were present in most of the participating centres $(9 ; 75 \%)$

- The study identified a need for national policy on the establishment and functioning of DTCs in healthcare facilities to improve future use of medicines in hospitals in Nigeria

\section{Funding}

This paper was not funded

\section{Declaration of interest}

The authors have no relevant affiliations or financial involvement with any organization or entity with a financial interest in or financial conflict with the subject matter or materials discussed in the manuscript. This includes employment, consultancies, honoraria, stock ownership or options, expert testimony, grants or patents received or pending, or royalties. 


\section{Reviewer disclosures}

Peer reviewers on this manuscript have no relevant financial or other relationships to disclose.

\section{Author Contribution}

Conception and study design - J Fadare, O Olayinka, L Gustafsson. Analysis and interpretation - J Fadare, R Obiako, S Orubu, B Godman. Drafting of manuscript - J Fadare, O Enwere, A Ajemigbitse, $S$ Orubu. Revision of manuscript for intellectual content - B Godman, L Gustafsson, E Enato, J Meyer, A Massele. Final approval of manuscript - All co-authors

\section{Acknowledgements}

The authors are grateful to respondents for timely return of completed questionnaires and their cooperation.

\section{References}

Papers of special note have been highlighted as:

* of interest

${ }^{* *}$ of considerable interest

1. Mao W, $\mathrm{Vu} \mathrm{H}, \mathrm{Xie} \mathrm{Z}$ et al. Systematic review on irrational use of medicines in China and Vietnam. PLoS One. 2015;10(3):e0117710.

2. Jain S, Upadhyaya $\mathrm{P}$, Goyal $\mathrm{J}$ et al. A systematic review of prescription pattern monitoring studies and their effectiveness in promoting rational use of medicines. Perspect Clin Res. 2015;6(2):86-90.

*This work gives a general background of non-rational use of medicines particularly in LMIC

3. Goossens H, Ferech M, Vander Stichele R, Elseviers M. Outpatient antibiotic use in Europe and association with resistance: a cross-national database study. Lancet. 2005;365(9459):579-87.

4. WHO ANTIMICROBIAL RESISTANCE. Global Report on Surveillance, Available at URL: http://www.euro.who.int/en/health-topics/disease-prevention/antimicrobialresistance/news/news/2014/04/new-report-antibiotic-resistance-a-global-health-threat [Cited 2018 Aug 24]

5. WHO. World Health Assembly addresses antimicrobial resistance, immunization gaps and malnutrition. Available at UTL: http://www.who.int/mediacentre/news/releases/2015/wha-25-may2015/en/. [Cited 2018 Aug 24]

6. O'Neill J. Securing new drugs for future generations: the pipeline of antibiotics. The review of antimicrobial resistance. Available at URL: https://amr-

review.org/sites/default/files/SECURING\%20NEW\%20DRUGS\%20FOR\%20FUTURE\%20GENERATI ONS\%20FINAL\%20WEB_0.pdf. [Cited 2018 Aug 24]

7. World Health Organization. 20th WHO Model List of Essential Medicines. 2017. Available at URL: http://www.who.int/medicines/news/2017/20th_essential_med-list/en/. [Cited 2018 Aug 25]

8. Hoffmann M. The right drug, but from whose perspective? A framework for analysing the structure and activities of drug and therapeutics committees. European journal of clinical pharmacology. 2013;69 Suppl 1:79-87.

**This work gives information about the structure and activities of Drugs and Therapeutis Committees in Europe. The study was also essential for comparison purposes.

9. Holloway KA, Henry D. WHO essential medicines policies and use in developing and transitional countries: an analysis of reported policy implementation and medicines use surveys. PLoS medicine. 2014;11(9):e1001724.

10. World Health Organization. Drug and therapeutics committees. A practical guide. Available at URL: http://apps.who.int/medicinedocs/en/d/Js4882e/. [Cited 2018 Aug 24]

${ }^{* *}$ This reference gives information about the process of setting up DTCs. Very important for the foundation of study and also for comparison

11. Management Sciences for Health and World Health Organization. Drug and Therapeutics Committee Training Course. 2007. Available at URL:

http://apps.who.int/medicinedocs/en/d/Js22115en/ [Cited 2018 Aug 24] ${ }^{* *}$ This reference gives information about the process of setting up DTCs. Very important for the foundation of the study and also for comparison 
12. Bjorkhem-Bergman L, Andersen-Karlsson E, Laing $R$ et al. Interface management of pharmacotherapy. Joint hospital and primary care drug recommendations. European journal of clinical pharmacology. 2013;69 Suppl 1:73-8.

13. Gustafsson LL, Wettermark B, Godman B et al. The 'wise list'- a comprehensive concept to select, communicate and achieve adherence to recommendations of essential drugs in ambulatory care in Stockholm. Basic \& clinical pharmacology \& toxicology. 2011;108(4):224-33.

14. Eriksen J, Gustafsson LL, Ateva K et al. High adherence to the 'Wise List' treatment recommendations in Stockholm: a 15-year retrospective review of a multifaceted approach promoting rational use of medicines. BMJ open. 2017;7(4):e014345.

15. Eriksen J, Ovesjo ML, Vallin M et al. Primary care physicians report high trust in and usefulness of the Stockholm drug and therapeutic committee's list of recommended essential medicines (the 'Wise List'). Eur J Clin Pharmacol. 2018;74(1):131-138

${ }^{*}$ This reference reflects the experience of primary care physicians in Sweden with drug formulary developed by the DTC of the Stockholm's City Council. Useful for information on the benefits of DTCs and also for comparison16. Collao JF, Smith F, Barber N. Selection of medicines in Chilean public hospitals: an exploratory study. BMC Health Serv Res. 2013;13:10.

17. Lima-Dellamora Eda C, Caetano R, Gustafsson LL et al. An analytical framework for assessing drug and therapeutics committee structure and work processes in tertiary Brazilian hospitals. Basic \& clinical pharmacology \& toxicology. 2014;115(3):268-76.

${ }^{* *}$ This paper assessed the structure and work processes of DTCs in Brazilian hospitals - very important to compare with results of this study

18. Matlala M, Gous AG, Godman B, Meyer JC. Structure and activities of pharmacy and therapeutics committees among public hospitals in South Africa; findings and implications. Expert Rev Clin Pharmacol. 2017;10(11):1273-128019. Odeyemi IA, Nixon J. Assessing equity in health care through the national health insurance schemes of Nigeria and Ghana: a review-based comparative analysis. Int J Equity Health. 2013;12:9.

20. Fadare JO, Adeoti AO, Desalu OO et al. The prescribing of generic medicines in Nigeria: knowledge, perceptions and attitudes of physicians. Expert review of pharmacoeconomics \& outcomes research. 2016;16(5):639-50.

21. Federal Ministry of Health Nigeria. National Drug Policy - Nigeria. Available at http://collections.infocollections.org/whocountry/en/d/Js6865e/8.html [cited 2018 Oct 28]

22. Nigeria [Internet]. 2016. Available from:

http://data.un.org/CountryProfile.aspx?crName=NIGERIA. Accessed August 24, 2018

23. Federal Ministry of Health of Nigeria. List of federal government owned tertiary hospitals Available from: http://www.health.gov.ng/index.php/department/hospital-services. [Cited 2018 Aug 24] 24. Map of Nigeria. Available from

https://www.nigerianmuse.com/20100527092749zg/sections/pictures-maps-cartoons/maps-ofvarious-states-and-their-local-governments-in-nigeria/ [cited 2018 Oct 27]

25. Management Sciences for Health and World Health Organization. 2007. Drug and Therapeutics Committee Training Course. Available at URL: http://www.who.int/medicines/technical_briefing/tbs/Trainer-s-Guide-All-Sessions.pdf. [Cited 2018 Aug 24]

26. Schiff GD, Galanter WL, Duhig J et al. A prescription for improving drug formulary decision making. PLoS medicine. 2012;9(5):1-7.

27. Nigeria Federal Ministry of Health. National Code of Health Research Ethics - National Health Research Ethics Committee. Available at URL: http://www.nhrec.net/nhrec/NCHRE_Aug\%2007.pdf. [Cited 2018 Aug 25]

28. Marques DC, Zucchi P. [Pharmacy and therapeutics committees in Brazil: lagging behind international standards]. Revista panamericana de salud publica. 2006;19(1):58-63.

29. Duran-Garcia E, Santos-Ramos B, Puigventos-Latorre F, Ortega A. Literature review on the structure and operation of Pharmacy and Therapeutics Committees. International journal of clinical pharmacy. 2011;33(3):475-83.

30. Weekes LM, Brooks C. Drug and Therapeutics Committees in Australia: expected and actual performance. British journal of clinical pharmacology. 1996;42(5):551-7.

31. Godman B, Wettermark B, Hoffmann M et al. Multifaceted national and regional drug reforms and initiatives in ambulatory care in Sweden: global relevance. Expert review of pharmacoeconomics \& outcomes research. 2009;9(1):65-83.

32. Van Dijck C, Vlieghe E, Cox JA. Antibiotic stewardship interventions in hospitals in low-and middle-income countries: a systematic review. Bull World Health Organ. 2018;96(4):266-80 
33. Mittmann N, Knowles S. A survey of Pharmacy and Therapeutic committees across Canada: scope and responsibilities. The Canadian journal of clinical pharmacology. 2009;16(1):e171-7.

*This paper described the situation of DTCs in Canada. Relevant for comparison

34. Thurmann PA, Harder S, Steioff A. Structure and activities of hospital drug committees in Germany. European journal of clinical pharmacology. 1997;52(6):429-35.

This paper described the situation of DTCs in Germany - relevant for comparison

35. Laupacis A, Anderson G, O'Brien B. Drug policy: making effective drugs available without bankrupting the healthcare system. HealthcarePapers. 2002;3(1):12-30.

36. Howard DH, Bach P, Berndt ER, Conti RM. Pricing in the Market for Anticancer Drugs. Journal of Economic Perspectives. 2015;29(1):139-62.

37. Cohen JP, Felix A. Are payers treating orphan drugs differently? Journal of Market Access \& Health Policy. 2014;2(1):23513.

38. van Vonderen MG, Gyssens IC, Hartwig NG et al. [Optimalisation of the antibiotic policy in The Netherlands. XI. The national electronic antibiotic guide 'SWAB-ID' for use in hospitals]. Nederlands tijdschrift voor geneeskunde. 2006;150(46):2560-4.

39. Lancaster R. Improving access to health treatment guidelines through mobile technology. $S$ Afr Pharm J. 2016;83(10):42-4.

40. Federal Republic of Nigeria. Essential Medicines List (Fifth Revision). In: Federal Ministry of Health, editor. 2010. Available online at http://apps.who.int/medicinedocs/en/d/Js19018en/. [Cited 2018 June 25]

41. Truter I, Shankar S, Bennie M et al. Initiatives in South Africa to enhance the prescribing of generic proton pump inhibitors: findings and implications. Journal of comparative effectiveness research. 2015;4(2):123-31.

42. Cameron A, Mantel-Teeuwisse AK, Leufkens HG, Laing RO. Switching from originator brand medicines to generic equivalents in selected developing countries: how much could be saved? Value in health. 2012;15(5):664-73.

43. Godman B, Bishop I, Finlayson AE et al. Reforms and initiatives in Scotland in recent years to encourage the prescribing of generic drugs, their influence and implications for other countries. Expert review of pharmacoeconomics \& outcomes research. 2013;13(4):469-82.

44. Khan B, Godman B, Babar A et al. Assessment of active pharmaceutical ingredients in the registration procedures in Pakistan: implications for the future. GaBI Journal. 2016;5(4):154-63.

45. Nakwatumbah S, Kibuule D, Godman B et al. Compliance to guidelines for the prescribing of antibiotics in acute infections at Namibia's national referral hospital: a pilot study and the implications. Expert review of anti-infective therapy. 2017;15(7):713-21.

46. Niaz Q, Godman B, Massele A et al. Validity of World Health Organisation prescribing indicators in Namibia's primary healthcare: findings and implications. International journal for quality in health care. 2018

47. Brax H, Fadlallah $\mathrm{R}, \mathrm{Al}-\mathrm{Kh}$ haled $\mathrm{L}$ et al. Association between physicians' interaction with pharmaceutical companies and their clinical practices: A systematic review and meta-analysis. 2017;12(4):e0175493.

48. Lotfi T, Morsi RZ, Rajabbik MH et al. Knowledge, beliefs and attitudes of physicians in low and middle-income countries regarding interacting with pharmaceutical companies: a systematic review. BMC health services research. 2016;16:57.

49. Lessing C, Ashton T, Davis P. The impact on health outcomes and healthcare utilisation of switching to generic medicines consequent to reference pricing: the case of lamotrigine in New Zealand. Applied health economics and health policy. 2014;12(5):537-46.

50. Civaner M. Sale strategies of pharmaceutical companies in a "pharmerging" country: the problems will not improve if the gaps remain. Health policy. 2012;106(3):225-32.

51. Fadare JO, Oshikoya KA, Ogunleye $\mathrm{OO}$ et al. Drug promotional activities in Nigeria: impact on the prescribing patterns and practices of medical practitioners and the implications. Hospital practice. 2018;46(2):77-87

52. Dean J, Loh E, Coleman JJ. Pharmaceutical industry exposure in our hospitals: the final frontier. Med J Aust. 2016;204(1):20-2.

53. Leong TD Munsamy J RM, Gray A. Selection of Essential Medicines in South Africa - A Work in Progress. S Afr Pharm J 2015;82(3):39 -41.

54. Weekes LM, Day RO. The application of adverse drug reaction data to drug choice decisions made by pharmacy and therapeutics committees. An Australian perspective. Drug Safety. 1998;18(3):153-9. 
55. Lipsy RJ. Institutional formularies: the relevance of pharmacoeconomic analysis to formulary decisions. PharmacoEconomics. 1992;1(4):265-81.

56. Mori AT, Kaale EA, Ngalesoni $F$ et al. The role of evidence in the decision-making process of selecting essential medicines in developing countries: the case of Tanzania. PLoS One. 2014;9(1):e84824.

57. Perumal-Pillay VA, Suleman F. Selection of essential medicines for South Africa - an analysis of in-depth interviews with national essential medicines list committee members. BMC health services research. 2017;17(1):17.

58. Odedina FT, Sullivan J, Nash R, Clemmons CD. Use of pharmacoeconomic data in making hospital formulary decisions. American journal of health-system pharmacy. 2002;59(15):1441-4.

59. Terblanche A, Meyer JC, Godman B, Summers RS. Knowledge, attitudes and perspective on adverse drug reaction reporting in a public sector hospital in South Africa: baseline analysis. Hosp Pract. 2017;45(5):238-245

60. Obebi Cliff-Eribo K, Sammons $\mathrm{H}$ et al. Adverse drug reactions in Nigerian children: a retrospective review of reports submitted to the Nigerian Pharmacovigilance Centre from 2005 to 2012. Paediatrics and international child health. 2016:1-5.

61. Oreagba IA, Oshikoya KA. Adverse reactions to fluoroquinolones in the Nigerian population: an audit of reports submitted to the National Pharmacovigilance Centre from 2004 to 2016. 2017;5(2):e00297.

62. South African National Department of Health. Norms and Standards Regulations Applicable to Different Categories of Health Establishments. 2017. Available at URL: Available at URL: http://www.samed.org.za/Filemanager/userfiles/national-health-act-61-2003-norms-and-standardsregulations-applicable-to-different-categories-of-health-establishments_20170104-GGN-4053900010.pdf. [Cited 2018 Aug 24]

63. South African National Department of Health. National Policy for the Establishment and Functioning of Pharmaceutical and Therapeutics Committees in South Africa. 2015. Available at URL: http://www.health.gov.za/index.php/pharmaceutical-and-therapeutics-committees. [Cited 2018 Aug 24]

64. Meyer JC, Schellack N, Stokes $\mathrm{J}$ et al. Ongoing initiatives to improve the quality and efficiency of medicine use within the public healthcare system in South Africa; a preliminary study. Front Pharmacol. 2017 Nov 9;8:751. 